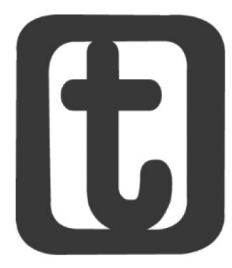

\title{
A FORMAÇÃO EM SERVIÇO SOCIAL NO BRASIL: CONTEXTO, CONFORMAÇÃO E PRODUÇÃO DE CONHECIMENTO NA ÚLTIMA DÉCADA
}

\author{
SOCIAL SERVICE FORMATION IN BRAZIL: CONTEXT, CONFORMATION \\ AND KNOWLEDGE PRODUCTION IN THE LAST DECADE
}

\author{
Alzira Maria Baptista Lewgoy ${ }^{1}$ \\ Ana Lucia Suarez Maciel $^{2}$ \\ Tatiana Reidel ${ }^{3}$
}

\section{RESUMO}

O artigo analisa o contexto, a conformação histórica e a produção de conhecimento sobre formação em Serviço Social no Brasil, no período de 2000 a 2010. O referido mapeamento sobre a formação evidenciou que, na última década, foram produzidas e publicizadas 525 produções materializadas em artigos publicados em anais de eventos (CBAS e ENPESS), em periódicos (Revistas Serviço Social \& Sociedade

\footnotetext{
1 Alzira Maria Baptista Lewgoy - Assistente Social, professora e pesquisadora do Curso de Serviço Social da Universidade Federal do Rio Grande do Sul. Doutora em Serviço Social pela Pontifícia Universidade Católica do Rio Grande do Sul. Endereço: Avenida Ramiro Barcelos 2600. Bairro Santa Cecília. Telefone: 51 99556870. E-mail: alziralewgoy@ufrgs.br

2 Ana Lúcia Suárez Maciel - Assistente Social, professora e pesquisadora da Faculdade de Serviço Social (Graduação e Pós-Graduação) da Pontifícia Universidade Católica do Rio Grande do Sul. Doutora em Serviço Social pela Pontifícia Universidade Católica do Rio Grande do Sul. Endereço: Avenida Ipiranga 6681/Prédio 15/3 andar. Telefone: 51 99686941. E-mail: ana.suarez@ pucrs.br

3 Tatiana Reidel: Assistente Social, professora e pesquisadora do Curso de Serviço Social da Universidade Federal do Rio Grande do Sul. Doutora em Serviço Social pela Pontifícia Universidade Católica do Rio Grande do Sul. Endereço: Avenida Ramiro Barcelos 2600. Bairro Santa Cecília. Telefone: 5191129663. E-mail: tatynhar@terra.com.br
} 
e Temporalis) e em teses e dissertações. No que se refere às estruturas de pesquisa, identificou-se a existência de 19 Grupos de Pesquisa que se debruçam sobre o tema e a sua inclusão incipiente nos programas de Pós-Graduação da área, já que apenas em 9 (30\%) dos 30 identificou-se a inclusão de disciplina relacionada à formação. Com base nesses elementos, problematiza essa realidade e o conhecimento que vem sendo produzido, demarcando os principais temas e desafios que se colocam para a formação profissional contemporaneamente.

Palavras-chave: Formação Profissional. Produção do Conhecimento. Serviço Social.

\section{ABSTRACT}

The article analyzes the context, historical conformation and knowledge production about Social Service formation in Brazil in the period of 2000 to 2010. The referred mapping revealed that, in the last decade, were produced and publicized 525 productions in the form of articles in scientific events (CBAS and ENPESS), journals (Magazine Serviço Social \& Sociedade and Temporalis) and in theses and dissertations. In relation to the research structures, were identified 19 Research Groups focused on this topic and the incipient inclusion in Post-graduation programs in the area, since that only in 9 (30\%) of the 30 was identified the inclusion of the subject related to formation. On the basis of these elements, it problematizes this reality and the knowledge that have been produced, demarcating the principal topics and challenges that are putted into the professional formation contemporaneously.

Keywords: Professional Formation. Knowledge Production. Social Service.

Submetido em 31/03/2013

Aceito em 20/05/2013

\section{INTRODUÇÃO}

Neste artigo, objetivamos compartilhar com a categoria profissional a sistematização e a problematização de um conjunto de questões relacionadas com os estudos que vínhamos fazendo, do lugar de pesquisadoras, docentes e militantes na área, acerca da conformação da formação na última década. Parte dessas questões vem emergindo dos estudos que realizamos por ocasião da elaboração das nossas teses de doutorado (LEWGOY, 2007; MACIEL, 2006; REIDEL, 2010), que se seguiram 
com as pesquisas empreendidas nos grupos de pesquisa ${ }^{4}$ que lideramos. Essas pesquisas, no último ano, somaram elementos relacionados com o esforço empreendido para mapear o estado da arte sobre a formação, a partir da nossa participação no Grupo Temático de Pesquisa (GTP) de Fundamentos, Formação e Trabalho Profissional5 da Associação Brasileira de Ensino e Pesquisa em Serviço Social (ABEPSS).

A partir desse conjunto de elementos, o artigo que apresentamos está estruturado da seguinte forma: num primeiro momento, será feito uma breve sistematização do contexto e da conformação histórica da formação em Serviço Social no Brasil no período 2000 a 2010 para, num segundo momento, apresentarmos o conhecimento que vem sendo produzido sobre o tema, com vistas à problematização desse conhecimento. Nosso intuito é sinalizar as principais temáticas e desafios que se colocam para a formação no tempo presente.

Não temos dúvida de que a formação em Serviço Social no nosso país teve alterações substantivas na última década. Sobre isso, ousamos afirmar que tais alterações são "inéditas" se compararmos sua trajetória histórica desde a criação do primeiro curso na década de 30 do século passado. De um lado, a particularidade do período de 2000 a 2010 deve-se às influências da própria política de educação superior vigente no país e, absolutamente, alinhada com as políticas internacionais. De outro lado, ao crescimento acelerado de cursos, especialmente privados, que alterou a geografia da formação, impondo movimentos da categoria profissional para a garantia da qualidade do seu projeto de formação (ABESS, 1996). A síntese desses elementos permite-nos afirmar que a conformação atual da formação em Serviço Social

4 Referimo-nos aos Grupos de Estudos e Pesquisas sobre Formação e Exercício Profissional em Serviço Social (GEFESS/UFRGS) e ao Grupo de Estudos e Pesquisas em Políticas de Ensino Superior e Formação em Serviço Social (FORMAS/PUCRS), ambos cadastrados na Plataforma dos Grupos de Pesquisa do CNPq.

5 Compuseram o GTP, além das autoras deste artigo, a professora Maria Rosângela Batistoni (UFJF), responsável pela ênfase dos fundamentos, e a professora Rosa Lucia Predes Trindade (UFAL), responsável pela ênfase do trabalho. A professora Katia Regina de Souza Lima (UFF) contribuiu com os trabalhos da ênfase da formação, além dos alunos que se vinculam aos Grupos de Pesquisa. 
complexificou-se enormemente, o que reforça a importância de tomá-la como objeto de estudo, bem como da militância da categoria profissional.

Assim, manter o espírito de luta impõe densidade para refletir sobre as balizas de sustentação da política de Educação Superior e seus rebatimentos na formação em serviço social, considerando as tendências postas no bojo da reforma universitária e a precarização das condições e relações de trabalho sob a égide da ofensiva neoliberal.

\section{CONTEXTUALIZAÇÃO DA EDUCAÇÃO SUPERIOR NO BRASIL E OS SEUS REBATIMENTOS NA FORMAÇÃO EM SERVIÇO SOCIAL}

A crise do capital que se agudizou na década de 1970, repercutindo em nível mundial e, com isso, agravando as desigualdades sociais, desencadeou a necessidade de expansão do capital, inclusive, no rentável campo do ensino superior. Nesse contexto, a partir da década de 1980, a orientação política sob inspiração neoliberal começou a ser implementada no Brasil, impulsionada por organismos internacionais, como o Fundo Monetário Internacional e o Banco Mundial (LIMA, 2007). Assim, as políticas sociais vêm sofrendo grandes impactos, pois perdem progressivamente o seu caráter de direito, transformando-se em serviços para o mercado. O mercado, por sua vez, expande-se, cada vez mais, pela alta possibilidade de lucratividade, e o que se evidencia é a desregulamentação de direitos, transformando, também, a educação em mercadoria.

A década de 1990 definiu estruturalmente esse ciclo do Estado como financiador do capital, no qual não há uma reforma estrutural de bases, mas apenas são implementadas políticas focais. Isso se confirmará, a seguir, com os dados históricos desse período na particularidade da política educacional.

Uma breve análise sobre o sistema de educação brasileiro, nessas últimas décadas, permite-nos observar o processo de reestruturação do capital, ocorrendo um conjunto de reformas em todos os níveis da educação, principalmente na educação superior e no ensino em Serviço Social, como evidenciam alguns pesquisadores da área (DAHMER, 2008; LIMA, 2007; MACIEL, 2006). 
A Lei de Diretrizes e Bases da Educação (LDB), regulamentada em 1996, abriu caminhos para uma série de alterações na política de ensino superior, com destaque para o Ensino a Distância (EAD). Até esse período, os cursos a distância eram utilizados para a oferta de cursos profissionalizantes e de complementação de estudos. $O$ estímulo maior à política de ensino superior via EAD deu-se a partir de 2003 com a contrarreforma universitária no governo Lula. Foram muitos os decretos, medidas provisórias e leis sendo implementadas. O resultado dessa contrarreforma foi a proliferação de matrículas no ensino superior privado, em especial na EAD. A partir de 2006, a modalidade a distância começou a ser implementada nos cursos de Serviço Social e, desde então, muitos debates surgiram pela iniciativa dos profissionais e dos órgãos representativos da profissão.

Lewgoy e Maciel (2008) sinalizam a contradição que envolve o projeto da reforma universitária, pois a legislação diz que a proposta da reforma é de fortalecimento da universidade pública, seguida pelo aumento significativo do número de IES privadas. Essa mudança tem implicações no fortalecimento do setor privado. As autoras relacionam isso ao projeto de orientação neoliberal, preconizado pelos organismos internacionais e à "corrida" desenvolvimentista dos países que precisam alavancar a inserção dos cidadãos na educação superior.

No que se refere aos cursos de graduação a distância em Serviço Social, eles foram autorizados a funcionar a partir de 2004 e começaram o funcionamento efetivo a partir de 2006, segundo informações do Cadastro Nacional das Instituições de Educação Superior do Instituto Nacional de Estudos e Pesquisas Educacionais/Ministério da Educação (INEP/MEC). Desde então, iniciou-se a expansão dessa modalidade em nível nacional, o que culminou com milhares de alunos matriculados.

Uma série de fatos históricos permite-nos apreender esse processo, a começar com a Declaração de Bologna, em 1999, seguida, no mesmo ano, do Documento do Banco Mundial sobre as Estratégias do Banco para a Educação na América Latina e Caribe (BANCO MUNDIAL, 1999), onde a educação é vista como instrumento de preparação para o mercado de trabalho e de 
dominação ideológica associada à visão do mundo empresarial. Em outras palavras: passa a ser vista como um serviço e passível de ser comercializada.

Consideramos importante destacar alguns elementos históricos para orientar a reflexão sobre as mudanças e desafios que se colocam aos assistentes sociais na última década, no que se refere à formação profissional. Assim, destaca-se, nos anos 2000, uma Comunicação dos Estados Unidos na Organização Mundial do Comércio, que marca o início da inclusão da educação superior no rol de serviços dessa organização.

Em 2002, foram estabelecidas as Diretrizes Curriculares da área de Serviço Social pelo MEC (Resolução 15/2002). Nessa conjuntura, é indispensável historiar que a disputa pelo projeto de formação profissional foi intensa entre a ABESS (hoje ABEPSS), que liderava a articulação e a construção coletiva da proposta das diretrizes no MEC. Esse Ministério, porém, suprimiu partes fundamentais do texto encaminhado pela comissão de especialistas, esvaziando as funções dessa comissão, bem como buscando uma padronização das diretrizes, impondo um projeto formativo distinto do previsto pela categoria. Descaracterizou, assim, a proposta de formação crítica e direção social da formação e

[...] os conhecimentos e habilidades preconizados
e considerados essenciais ao desempenho do as-
sistente social. Esses elementos, exaustivamente
debatidos pelo conjunto das unidades de ensino,
sofreram cortes que comprometem o projeto ori-
ginal proposto ao Conselho Nacional de Educação
(IAMAMOTO, 2008, p. 445).

Neste contexto de implementação de uma política educacional alinhada a uma cultura mercadológica, Mendes (2011) reflete e problematiza sobre a direção dada pelo MEC que, na época, inclusive, pela redução da carga horária mínima dos cursos de graduação, com prejuízos significativos para a formação do assistente social. A proposta entraria em votação no Conselho Nacional de Educação (CNE) para uma redução de 3.220 h/a para $2.400 \mathrm{~h} / \mathrm{a}$, desencadeando uma mobilização nacional entre as entidades organizativas da profissão, que resultou na aprovação de 3.000 h/a para a formação da área no país. 
Na avaliação de Cassab (2011), o governo na época se posicionou alicerçado numa política que pretendia submeter a educação e a universidade, em particular, às regras do mercado, tanto no campo privilegiado da acumulação, quanto como no intento de fazer da universidade uma emissora de certificados, esvaziada de seu papel de produtora de conhecimento.

Nesse cenário, destaca-se também a graduação a distância. Sobre essa modalidade, o artigo 80 da LDB (1996) explicita a seguinte orientação: "o Poder Público incentivará o desenvolvimento e a veiculação de programas de ensino à distância em todos os níveis e modalidades de ensino, e de educação continuada". Além disso, o parecer 301/MEC que autorizou as IES e Centros Universitários a ofertarem cursos a distância foi promulgado em 2003.

Na esteira das mudanças em curso na política de educação superior do início do século XXI, no Brasil, sublinhamos a gestão de Tarso Genro (2003/2004), na qual foi apresentada a primeira versão do Projeto de Lei da Reforma da Educação Superior no país. Também, nesse período (2004), foi aprovado o Sistema Nacional de Avaliação do Ensino Superior (SINAES), institucionalizando o papel do Estado como avaliador da política e a Gratificação pelo Exercício da Docência (GED), materializando a avaliação individual dos docentes por desempenho. O Programa Universidade para todos (PROUNI), conformando a esfera pública não-estatal, mediante a compra de vagas públicas em IES privadas com incentivos fiscais. Também é apresentado o PL 3627/Política de Cotas, num esforço para dar respostas às históricas desigualdades de acesso das "minorias" ao ensino superior; e a portaria 4059/MEC que aprova a inclusão da modalidade do ensino semipresencial em até $20 \%$ da carga horária total dos cursos de graduação no país, estimulando o EAD também no ensino presencial.

Concomitantemente, ainda no ano de 2004, temos a autorização da oferta do Curso de Serviço Social na modalidade a distância, embora o curso tenha iniciado apenas em 2006. Nesse mesmo ano, o conjunto CFESS/CRESS contrário à essa modalidade de ensino manifesta essa posição em uma nota pública. $\mathrm{Na}$ perspectiva de contribuir com a formação e um exercício 
qualificado, divulga, também, a Resolução CFESS 433/2006, que versa sobre as condições éticas e técnicas do exercício profissional do Assistente Social.

Na esteira das rápidas e intermitentes mudanças na política de educação superior, o ano de 2007 indica a criação do Programa de Apoio a Planos de Reestruturação e Expansão das Universidades Federias (REUNI), responsável pela ampliação significativa das IFES e materializada pela construção de novas instituições; abertura de novos cursos, inclusive na área do Serviço Social; realização de concursos públicos para docentes e técnicos administrativos; abertura de novas vagas nesse âmbito de ensino. Um importante ganho para os estudantes materializa-se com a aprovação da Política Nacional de Assistência Estudantil (PNAES).

A gestão de Fernando Haddad (2005/10) apresentou, no ano de 2007, a quarta versão do Projeto de Lei da Reforma da Educação Superior no país, evidenciando o interesse estatal na referida lei e a resistência em aprová-la, embora a mesma venha se materializando por outros movimentos (decretos, portarias, etc). Nesse mesmo ano, o MEC apresenta os Referenciais de Qualidade para a EAD no país, tendo em vista o crescimento acelerado (369.766 matrículas são registradas nessa ocasião) sem a respectiva e necessária regulação estatal. O Parecer Jurídico do CFESS (10/2007), encaminhado aos CRESS com orientações para a fiscalização dos requisitos obrigatórios para validação dos cursos na modalidade a distância, sinaliza a tentativa dos órgãos de representação da categoria em garantir a qualidade da formação na área. Na mesma direção, é constituída uma Comissão do CFESS/ABEPSS para acompanhar o EAD na área, em face da rápida e descontrolada expansão.

O ano de 2008 reforçou os movimentos da categoria, contrários à modalidade do EAD, como se constata durante $037^{\circ}$ Encontro Nacional do CFESS/CRESS, que explicitou o posicionamento contrário das organizações da categoria profissional e a preocupação com a qualidade da formação na modalidade a distância. Nesse mesmo ano, é aprovada a Lei 11.788/2008 (Lei dos Estágios no país), a fim de regular essa prática em todo o território nacional, com impactos significativos no reordenamento das IFES, 
bem como dos agentes de intermediação dos estágios. Alinhada com as necessidades de regulação e no compasso do tempo histórico, o CFESS emitiu a Resolução 533/2008, que regulamentou a supervisão de estágio em Serviço Social, uma demanda histórica da profissão e um importante ganho para as UFAS na direção da qualidade da formação e do exercício da supervisão na área.

Em 2009, durante o $38^{\circ}$ Encontro Nacional do CFESS/CRESS, em Campo Grande, foi elaborada a "Carta Aberta aos Estudantes e Trabalhadores dos Cursos de Serviço Social do Brasil”, na perspectiva de luta contra a precarização do ensino e do trabalho profissional. Nesse mesmo ano, foi aprovado o Plano de Trabalho da Gestão 2009-2010 da ABEPSS, que incluiu a luta contra a precarização e o aligeiramento do ensino, especialmente, na modalidade a distância, como compromisso orientador geral dessa gestão. E, também, nos brindou com uma importante conquista: a formulação da Política Nacional de Estágio (ABEPSS), coletivamente construída, que materializou uma das ações prioritárias dessa gestão, expressando a luta contra a precarização do ensino superior e a busca incansável pela sua qualidade.

A expansão desenfreada do ensino superior pode ser evidenciada no ano de 2010, quando atingimos, por exemplo, 930.179 matrículas na modalidade a distância em todo o país. Dentre os Cursos mais procurados, estão Pedagogia, Administração e Serviço Social (INEP, 2011). Constatamos que, nesse período, na área do Serviço Social, 14 IES, dentre os quais apenas um é público, ofertam essa modalidade de ensino. Como forma de resistência à precarização, o coletivo CFESS/CRESS/ENESSO/ABEPSS publica o material intitulado "Sobre a incompatibilidade entre graduação à distância e Serviço Social", que teve uma importante contribuição para o debate e para fortalecimento da qualidade do ensino em Serviço Social.

A reedição pelo CFESS/CRESS/ENESSO/ABEPSS do material intitulado "Sobre a incompatibilidade entre graduação à distância e Serviço Social”, ocorre no ano de 2011, acompanhada da campanha em defesa da formação de qualidade "Educação não é fast-food: diga não para a graduação à distância em Serviço Social". Ambos os documentos tiveram sua circulação proibida 
por determinação judicial, o que evidencia a força da categoria em utilizar estratégias de comunicação como forma de publicização da realidade da formação na área.

Entretanto, a ofensiva capitalista no mercado da educação superior segue o seu curso. Como mera ilustração, trazemos os dados da realidade norte-americana que, no ano de 2012, revelou o aumento de matrículas na modalidade de ensino a distância, com assustadores dados que sinalizam a subida em $58 \%$ das matrículas nessa modalidade e a queda entre $5 \%$ e $15 \%$, na modalidade presencial. (EDUCAÇÃO..., 2013, extraído da Internet).

No cenário brasileiro, os dados do MEC, divulgados em $16 / 10 / 2012$, informam que temos 2.365 IES, das quais são 284 públicas e 2.081 são privadas. Nesse número, 190 são universidades, 131 centros universitários, 2.004 são faculdades e 40 institutos federais e Cefets. No total, 5.746.762 alunos estão matriculados no ensino presencial e 992.927 na educação a distância.

Nesse mesmo ano, o número de matrículas nos cursos de Serviço Social chegou em 143.198, sendo 109.663 em UFAS privadas (75\%) e 33.535 em UFAS públicas (25\%). Dessas matrículas, 56.815 referiam-se à modalidade a distância (525) e 52.848 à modalidade presencial (48\%). O número de concluintes foi de 20.017 alunos, sendo 9.287 na modalidade presencial (46\%) e 8.925 na modalidade a distância (44\%). Convém, também, fazer uma comparação da oferta desses cursos com a modalidade presencial que, ainda segundo dados do MEC, referentes a agosto de 2012, totalizavam 511 UFAS (311 presenciais e 194 à distância). Com esses dados, podemos afirmar que a formação em Serviço Social no Brasil, na atualidade, é predominantemente privada (75\%), a distância (52\%) e com egressos ainda, majoritariamente, de cursos presenciais (46\%).

Segundo dados do CFESS, o contingente profissional indicava 110.000 assistentes sociais, o que significa que, pela primeira vez na história da profissão, o número de alunos supera o de profissionais, o que confirma a tese de lamamoto (2008) acerca da formação de um exército assistencial de reserva. 
Os dados e fatos históricos evidenciam o quanto a última década trouxe mudanças estruturais na política de educação superior no nosso país, as quais podem ser sintetizadas num movimento de contrarreforma do Estado, com uma tensa disputa pela noção de "público" e de "direito" no acesso a essa modalidade de ensino. Essa afirmação materializa-se com base nos dados comprobatórios de que estamos diante de um modelo de Estado, que vem promovendo a reforma universitária "aos pedaços", mesmo que ainda não tenha tido o seu projeto aprovado; que promove a expansão da educação superior mediante o estímulo e a parceria com a iniciativa privada; que fomenta a educação superior a distância e que se institucionaliza como um Estado majoritariamente regulador e pouco executor, tendo em vista as inúmeras iniciativas em regular esse ensino e as escassas ações para ampliação, acesso e permanência em instituições públicas e presenciais.

Diante desse contexto, também tratamos de ilustrar brevemente como a categoria profissional foi respondendo a esse modelo de Estado, cabendo indicar como essas questões vêm sendo incorporadas nos grupos de pesquisa, nos Programas de Pós-Graduação e na produção de conhecimento sobre a formação em Serviço Social.

\section{A PRODUÇÃO DE CONHECIMENTO SOBRE FORMAÇÃO EM SERVIÇO SOCIAL: TENDÊNCIAS E DESAFIOS}

Para apresentar e problematizar a produção de conhecimento sobre a formação em Serviço Social, na última década, utilizamos os dados obtidos junto ao trabalho de mapeamento dessa produção, empreendido no ano de 2012 junto ao GTP da ABEPSS, ênfase da Formação, que foram sistematizados, em uma primeira versão, em um artigo publicado nos Anais do último ENPESS ${ }^{6}$.

No referido mapeamento, foram levantadas as estruturas de pesquisa sobre Formação, vinculadas aos Programas de PósGraduação em Serviço Social. Nesse mapeamento, foram localizados 19 Grupos de Pesquisa que possuem a formação como

6 Artigo intitulado: "A produção de conhecimento sobre formação em Serviço Social: aproximações com o estado da arte”. 
objeto de estudo <http://carloschagas.cnpq.br>. No contexto da Pós-Graduação Strictu Sensu, foram identificados 31 Programas, dentre os quais um está em fase de implantação, como se constata no Quadro 1.

Quadro 1 - Demonstrativo das estruturas de

Pesquisa em Serviço Social no Brasil

\begin{tabular}{|c|c|c|}
\hline $\begin{array}{c}\text { ESTRUTURAS DE } \\
\text { PESQUISA }\end{array}$ & TOTAL & DESCRIÇÃO \\
\hline $\begin{array}{c}\text { GRUPOS DE } \\
\text { PESQUISA } \\
\text { (Cadastrados na } \\
\text { Plataforma Carlos } \\
\text { Chagas do CNPq) }\end{array}$ & 19 & $\begin{array}{l}04 \text { em São Paulo } \\
01 \text { no Pará } \\
03 \text { no Rio de Janeiro } \\
01 \text { em Santa Catarina } \\
03 \text { em Porto Alegre } \\
02 \text { na Bahia } \\
01 \text { em Tocantins } \\
03 \text { em Minas Gerais } \\
01 \text { no Sergipe }\end{array}$ \\
\hline $\begin{array}{c}\text { Cursos de Pós- } \\
\text { Graduação em } \\
\text { Serviço Social } \\
\text { (Em funcionamento } \\
\text { segundo a CAPES) }\end{array}$ & 31 & $\begin{array}{l}30 \text { Programas em funcionamento e } 1 \\
\text { em organização } \\
10 \text { Programas possuem disciplinas } \\
\text { relacionadas ao tema da Formação }\end{array}$ \\
\hline
\end{tabular}

Fonte: Grupo de Estudos e Pesquisas sobre Formação e Exercício profissional (GEFESS, 2012).

Com base no Quadro 1, no que se refere aos Programas de Pós- Graduação no Brasil, verifica-se que, dos 31 programas constantes no portal da CAPES, 30 estão em funcionamento e 1, embora aprovado, encontra-se em fase de organização. Esses programas encontram-se nas seguintes regiões: Norte: AM (1), PA (1); Centro-Oeste: DF (1), MT (1), GO (1); Sul: RS (2), SC (1), PR (1); Sudeste: MG (2), ES (2), RJ (5), SP (3); Nordeste: MA (1), PI (1), BA (1), $A L$ (1), PB (2), PE (1), RN (1), SE (1), CE (1). Dos programas em funcionamento, destaca-se que 17 deles são voltados, exclusivamente, para a área do Serviço Social, sendo 7 cursos apenas com mestrado e 10 cursos com mestrado e doutorado. No que se refere à natureza das instituições de ensino que ofertam esses cursos, 8 são privadas e 23 são públicas, sendo 18 federais e 5 estaduais, o que nos permite constatar que, contrariamente à graduação, a pós-graduação é feita majoritariamente em instituições públicas. 
Com relação às disciplinas voltadas à Formação, é possível identificar que 9 programas atuam com temas relacionados, através da oferta de disciplinas descritas como, por exemplo: Formação, Cultura Profissional e Tendências do Serviço Social Contemporâneo; Ensino e Prática Docente no Serviço Social; Fundamentos da Formação em Serviço Social; Políticas de Ensino Superior e Formação em Serviço Social; Serviço Social e Pensamento Marxista Tendências Atuais e Formação Profissional; Formação Profissional e Mercado de Trabalho do Serviço Social; Tópicos Especiais em Serviço Social, Fundamentos, Formação e Trabalho Profissional; Prática Docente; Dimensão Social nas Políticas Educacionais, Interface da Educação e do Serviço Social; Formação Profissional em Serviço Social: Elementos Constitutivos; Didática do Ensino Superior; Estágio de docência.

Essas estruturas de pesquisa, por sua vez, apresentam baixo número de Grupos de Pesquisa, bem como a insignificativa inclusão do tema da formação nos Programas de Pós-Graduação da área. Esses dados remetem a necessidade de problematização do tema da formação, em nível de pós-graduação. Se a formação contribui para o exercício profissional e este, por sua vez, é qualificado através da formação/educação permanente, cabem as indagações: Por que em nossos currículos o temas da formação, da educação, do ensino superior aparecem de maneira discreta ou quase inexpressiva? Se a pós-graduação é o espaço privilegiado da formação de docentes, como isso se dá com a ausência de disciplinas sobre o tema em todos os programas? Qual é a política de formação de docentes na pós-graduação do Serviço Social?

Já nos Anais de Congressos e Encontros da categoria, foi possível mapear 170 artigos nos Anais dos CBAS (Anos de 2001, 2004, 2007 e 2010) e 217 artigos nos Anais dos ENPESS (Anos de 2000, 2002, 2004, 2006, 2008 e 2010).

No âmbito da produção de conhecimento junto aos Programas de Pós-Graduação, a partir do levantamento feito nas Teses e Dissertações, disponíveis no Portal da CAPES, localizamos 31 dissertações e 7 teses <http://www.capes.gov.br>, totalizando 38 produções acadêmicas. 
Ainda empreendemos um mapeamento junto a dois periódicos de circulação na área que indicou 90 artigos, assim distribuídos: 20 artigos na Revista Serviço Social \& Sociedade (o critério para inclusão deste periódico foi ser a revista mais antiga e de maior circulação no país); 70 artigos na Revista Temporalis (o critério para a inclusão deste periódico foi o fato do mesmo ter sua linha editorial destinada para o tema da formação, bem como ser um produto da ABEPSS).

Em todos esses levantamentos, tomou-se como critério a busca pelas seguintes palavras chaves: diretrizes curriculares, formação permanente, educação superior, formação, educação, supervisão, ensino, política de ensino superior, educação permanente, docência, trabalho docente e ensino a distância.

A síntese com os indicadores quantitativos sobre a produção de conhecimento mapeada nas fontes indicadas totaliza, no período em análise, $\mathbf{5 2 5}$ produções, assim distribuídas:

Quadro 2 - Demonstrativo da produção bibliográfica em Serviço Social sobre formação profissional no período de 2000 a 2010.

\begin{tabular}{|c|c|c|c|c|c|c|c|c|c|c|c|c|c|}
\hline \multicolumn{2}{|c|}{\begin{tabular}{|r}
$\begin{array}{c}\text { Tipo de } \\
\text { Produção }\end{array}$ \\
ANO \\
\end{tabular}} & \multirow{2}{*}{\begin{tabular}{|r|}
2000 \\
10
\end{tabular}} & \multirow{2}{*}{$\begin{array}{c}2001 \\
-\end{array}$} & \multirow{2}{*}{\begin{tabular}{|r|}
2002 \\
17
\end{tabular}} & \multirow{2}{*}{\begin{tabular}{|c|}
2003 \\
-
\end{tabular}} & \multirow{2}{*}{\begin{tabular}{|r|}
2004 \\
41 \\
\end{tabular}} & \multirow{2}{*}{\begin{tabular}{|c|}
2005 \\
-
\end{tabular}} & \multirow{2}{*}{$\begin{array}{r}2006 \\
35\end{array}$} & \multirow{2}{*}{\begin{tabular}{|c|}
2007 \\
- \\
\end{tabular}} & \multirow{2}{*}{\begin{tabular}{|c|}
2008 \\
22 \\
\end{tabular}} & \multirow{2}{*}{\begin{tabular}{|c|}
2009 \\
-
\end{tabular}} & \multirow{2}{*}{\begin{tabular}{|l|}
2010 \\
102 \\
\end{tabular}} & \multirow{2}{*}{\begin{tabular}{|r|} 
Total \\
227
\end{tabular}} \\
\hline ANAIS & ENPESS & & & & & & & & & & & & \\
\hline EVENTO & CBAS & - & 31 & - & - & 32 & - & - & 43 & - & - & 64 & 170 \\
\hline \multicolumn{2}{|c|}{\begin{tabular}{|c|} 
REVISTAS \\
SERVIÇO SOCIAL \\
E SOCIEDADE \\
\end{tabular}} & 00 & 00 & 00 & 00 & 04 & 00 & 01 & 00 & 10 & 01 & 04 & 20 \\
\hline \multicolumn{2}{|c|}{$\begin{array}{c}\text { REVISTAS } \\
\text { TEMPORALIS } \\
\end{array}$} & 14 & 02 & 03 & 00 & 20 & 01 & 03 & 08 & 04 & 10 & 05 & 70 \\
\hline \multicolumn{2}{|c|}{ TESES } & - & - & 01 & 01 & - & - & 02 & 01 & 01 & 01 & - & 07 \\
\hline \multicolumn{2}{|c|}{ DISSERTAÇÕES } & 06 & 03 & 04 & 01 & - & 02 & 03 & 02 & 01 & 04 & 05 & 31 \\
\hline \multicolumn{2}{|c|}{$\begin{array}{c}\text { TOTAL DE } \\
\text { PRODUÇÕES }\end{array}$} & 30 & 36 & 25 & 02 & 97 & 03 & 44 & 54 & 38 & 16 & 180 & 525 \\
\hline
\end{tabular}

Fonte: Grupo de Estudos e Pesquisas sobre Formação e Exercício Profissional (GEFESS, 2012).

O quadro da produção bibliográfica e acadêmica em Serviço Social sobre formação profissional, no período de 2000 a 2010, nos eventos de promoção das entidades da categoria profissional 
(CBAS e ENPESS), evidencia uma produção de 397 artigos. Nos quatro CBAS ocorridos no período, totalizaram-se 3.896 trabaIhos apresentados. Destes, 170 referem-se à formação, ou seja, apenas $4,5 \%$ do total. A produção de conhecimento publicada nos anais do CBAS não possui uma regularidade na última década, sendo intercalada com anos de maior produção e posterior redução da mesma. Os temas relacionados à formação em Serviço Social possuem uma relativa linearidade nos Anais dos CBAS de 2001 a 2010. Essa linearidade acerca do tema da formação em Serviço Social é quebrada, no que se refere às palavras- chave: Educação a Distância e Supervisão. Ambas, no ano de 2010, possuíram um crescimento considerável em relação aos anos anteriores. A Educação a distância foi incorporada às publicações nos Anais do CBAS somente em 2007, com apenas um artigo sobre o tema. Porém, em 2010, houve um crescimento com nove artigos relacionados com o tema, o que se explica pela expansão dessa modalidade de ensino no mesmo período.

No ENPESS de 2000, dos 229 trabalhos apresentados, 33 foram sobre formação, desdobrados nos eixos da Saúde e da Formação Profissional, seguido dos eixos Gênero, Questão Agrária e Questão Urbana, Cultura, Identidade e Práticas Sociais, Política Social, Assistência e Previdência, Serviço Social e Formação Profissional, Processo de Trabalho e Serviço Social, Transformação no Mundo do Trabalho, Criança e Adolescente. Em 2002, do total de 427 produções, 38 foram sobre formação, sendo que destas, a maior concentração está no eixo Trabalho e Formação do Assistente Social, seguido dos eixos: Mundo do trabalho, Urbano e Rural e Sistema Sociopolítico. Em 2004, do total de 546 trabalhos, 45 produções versaram sobre Formação evidenciando uma maior concentração no eixo da Formação Profissional, seguido do eixo Articulação entre Formação e Exercício Profissional, bem como Educação Continuada. Em 2006, o total de trabalhos no evento cresceu, em relação aos anos anteriores, para 1.024. Mas, em proporção a produção de conhecimento sobre formação, a tendência é diminuir, evidenciando 33 trabalhos desdobrados no eixo de Fundamentos do Serviço Social, Formação Profissional e o Processo Interventivo do Serviço Social, Questão Social e Trabalho, Política Social. Em 
2008, o número total de trabalhos diminuiu para 851 e, acompanhando essa redução, a produção sobre formação foi de 21 trabalhos, distribuídos nos eixos Formação Profissional em Serviço Social, Processo Interventivo do Serviço Social, Fundamentos do Serviço Social, Questão Social e Trabalho. E no último ENPESS, de 2010, o total de trabalhos novamente aumentou para 1.110, configurando-se como maior evento em total de produção, e, igualmente, com o número de produções sobre formação, que cresceu para 103 trabalhos, distribuídos nos eixos Serviço Social, Fundamentos, Formação e Trabalho, sendo este o eixo de maior concentração de trabalhos, seguido o de Política Social e Serviço Social, Movimentos Sociais e Serviço Social, Classe Social, Gênero, Raça/Etnia, Geração, Diversos, Trabalho, Questão Social e Serviço Social.

Constata-se que há um crescimento da produção do conhecimento sobre a formação, acompanhando o movimento da produção em Serviço Social em geral. Em 2006, a produção sobre formação reduziu, mas, no último ENPESS (2010), houve um aumento significativo. O tema da formação também perpassou vários eixos, tendo maior concentração de trabalhos no eixo que vincula formação, Serviço Social, fundamentos, trabalho e ou exercício profissional, cujos dados confirmam o caminho e a relevância deste estudo.

Em relação aos artigos publicados nas revistas Serviço Social \& Sociedade e Temporalis ${ }^{7}$, contabilizou-se 91 artigos. 0 último periódico possui uma produção significativamente maior do que o primeiro, datado da última década, representando cerca de $76 \%$ do total das produções desse período. Enquanto a revista Temporalis produziu 19 artigos entre os anos de 2000 a 2002, a Revista Serviço Social \& Sociedade não teve produção nesse período. No ano de 2003, nenhuma das duas Revistas apresentaram produções que discutissem, diretamente, o tema da formação. Os anos de maior expressão de produção referente à formação

\footnotetext{
7 No levantamento realizado nas Revistas Serviço Social \& Sociedade e Temporalis, buscou-se identificar as produções que versavam sobre formação, a partir dos títulos dos artigos publicados, considerando que os títulos "anunciam a informação principal do trabalho ou indicam elementos que caracterizam o seu conteúdo" (FERREIRA, 2002, p. 261).
} 
concentram-se nos anos de 2000, 2004, 2008 e 2010. A Revista Temporalis atingiu seu pico em $2004 \mathrm{com}$ o total de 20 produções, e é evidenciado, na Revista Serviço Social \& Sociedade, o ano de 2008 como o de maior expressão de produção: 10 artigos. Constata-se, ainda, que o ano de 2004 foi o de maior produção, sendo um período em que a ABEPSS privilegiou, em sua gestão e na edição editorial, o tema "A formação profissional”, considerando o contexto da época, isto é, a grande tensão em relação às diretrizes curriculares para a formação dos cursos superiores, em especial, do Serviço Social.

No que se refere à produção acadêmica, as 31 dissertações e 7 teses que totalizam as 38 produções mapeadas debruçam-se, majoritariamente, no tema da supervisão (4 teses e 15 dissertações), seguidas dos temas: docência, currículo, universidade, ensino, competência, relação teoria-prática, produção de conhecimento, interdisciplinaridade, mercado de trabalho, ensino a distância, projeto ético-político, formação e sua interface com saúde e direitos humanos.

\section{CONCLUSÃO}

A pauta da formação em Serviço Social, nessa segunda década do século XXI, reatualiza-se a cada novo dado que nos chega e convoca a todos os pesquisadores, organizações da categoria profissional, Unidades de Formação, docentes, alunos e profissionais a seguir enveredando esforços por tornar esse objeto de estudo mais visível.

Este artigo se encerra, provisoriamente, e inscreve-se no movimento coletivo de pesquisadores que buscam contribuir para a apreensão da área, no que se refere ao contexto, à conformação e ao mapeamento da produção teórica sobre a formação que indicou, na última década, 525 produções (artigos em anais de eventos, em periódicos, teses e dissertações); a existência de 19 Grupos de Pesquisa que se debruçam sobre o tema e a inclusão incipiente do mesmo nos programas de Pós-Graduação, já que apenas em 9 (30\%) dos 30 se identificou a inclusão de disciplina relacionada à formação. 
No horizonte futuro das pesquisas que desenvolveremos, desenha-se a necessidade de mergulhar nessas produções e, a partir da sua análise, sinalizar as perspectivas que orientam as mesmas, com vistas ao adensamento do debate, à identificação das lacunas nessa produção coletiva e ao fornecimento de subsídios que permitam o fortalecimento do projeto de formação da área.

Inúmeras ações têm demonstrado que, como pesquisadores, somos capazes de superar as barreiras institucionais e geográficas que nos separam. Como exemplo disso, podemos citar a recente experiência vivenciada junto ao GTP da ABEPSS, por nós vivenciada, através da produção conjunta interinstitucional de grupos de pesquisa. Além disso, sabemos que o compromisso intelectual e a militância política se fortalecem a cada realidade adversa que se apresenta no horizonte da formação dos futuros assistentes sociais.

O tempo futuro ainda se apresenta com inúmeros desafios e possíveis reveses para as históricas conquistas que a profissão alcançou, mas sua filiação teórica a uma matriz crítica associada à sua grande capacidade organizativa parecem ser os meios para atravessarmos esse período sem comprometer a qualidade da formação que se deseja para os futuros assistentes sociais e demais cidadãos deste país.

\section{REFERÊNCIAS}

ASSOCIAÇÃO BRASILEIRA DE ENSINO EM SERVIÇO SOCIAL ABESS. CENTRO DE DOCUMENTAÇÃO E PESQUISA EM POLÍTICAS SOCIAIS E SERVIÇO SOCIAL - CEDEPSS. Proposta Básica para o projeto de formação profissional: novos subsídios para debate. Recife, 1996.

ASSOCIAÇÃO BRASILEIRA DE ENSINO E PESQUISA EM SERVIÇO SOCIAL - ABEPSS. Plano de Trabalho da Executiva Nacional 20092010. Rio de Janeiro, 2009.

ANAIS dos congressos brasileiros de assistentes sociais. CBAS. 1 CD-Room. (Período 2000 a 2010). 
ANAIS dos encontros nacionais de pesquisadores em serviço social - ENPESS. 1 CD-Room (Período 2000 a 2010).

BANCO MUNDIAL. La enseñanza superior: las lecciones derivadas de la experiencia. Washington, DC: Publicación del Banco Mundial, 1995. Disponível em: <http://www.scribd.com/doc/9333867/ Banco-Mundial-La-ensenanza-superior>. Acesso em: 10 jul. 2013.

BRASIL. Lei n 9.394, de 20 de dezembro de 1996. Estabelece as Diretrizes e Bases da Educação Nacional. Sancionada, em 12 de dezembro de 1996, pelo Presidente da República Federativa do Brasil.

. Ministério da Educação. Universidade XXI: Fundamentos para uma nova política de ensino superior. 1999.

. Exposição de motivos: Anteprojeto da Lei de Educação Superior. Disponível em: <www.mec.gov.br/reforma/cinco.asp >. Acesso em: 10 jul. 2013.

. Projeto de Reforma Universitária. Disponível em: <www. mec.gov.br/reforma>. Acesso em: 10 jul. 2013.

- Referenciais de Qualidade para a Educação Superior à distância. Brasília, 2007.

CASSAB, Maria Aparecida Tardin. ABEPSS Gestão 2001-2012. Revista Serviço Social \& Sociedade, Brasília: ABEPSS, ano 11, n. 22, jul./dez. 2011.

CASTRO, Moura; LEVY, Daniel C. A educação superior na América Latina e Caribe: Documento de Estratégia. Washington-DC, 1997. (Material Impresso).

CONSELHO FEDERAL DE SERVIÇO SOCIAL. Parecer Jurídico $\mathrm{n}^{\circ}$ 10/07. Oficio Circular CFESS, Brasília, n. 025/2007, abr. 2007.

- Posicionamento das Entidades Nacionais de Serviço Social sobre criação e proliferação de cursos de Graduação 
à Distância. Brasília: CFESS/CRESS/ABEPSS/ENESSO, 2007. Disponível em: <www.cfess.org.br>. Acesso em: 10 jul. 2013.

. Relatório Final do $37^{\circ}$ Encontro Nacional CFESS/CRESS. Brasília, 25 a 28 de Setembro de 2008. Disponível em: <www. cfess.org.br>. Acesso em: 10 jul. 2013.

. Carta Aberta aos Estudantes e Trabalhadores dos Cursos de Graduação a Distância em Serviço Social no Brasil. Campo Grande, 2009. Disponível em: <www.cfess.org.br>. Acesso em: 10 mar. 2013.

DAHMER . Larissa. Mercantilização do Ensino Superior Educação às Distância e Serviço Social. Revista Serviço Social \& Sociedade, Brasília: ABEPSS, ano VIII, n. 15, 2008.

EDUCAÇÃO a distância: blog brasileiro de educação a distância. Dados da educação superior: presencial e a distância. Disponível em: <http://www.educacaoadistancia.blog.br/dados-da-educacao-superior-presencial-e-a-distancia/>. Acesso em: 14 jul. 2013.

FERREIRA, Norma Sandra de Almeida. As pesquisas denominadas "estado da arte". Revista Educação \& Sociedade, ano XXIII, n. 79, ago. 2002.

GEFESS/UFRGS. GPESFSS/PUCRS. GEPESS/UFF. Relatório com subsídios para o GTP Serviço Social, Fundamentos, Formação e Trabalho Profissional da ABEPSS. Porto Alegre, 2012.

IAMAMOTO, Marilda Vilela. Serviço Social em tempos de capital fetiche: capital financeiro, trabalho e questão social. São Paulo: Cortez, 2007.

INSTITUTO NACIONAL DE PESQUISAS ANISIO TEIXEIRA - INEP. Censo da Educação Superior. 2011. Disponível em: <http://www. inep.gov.br>. Acesso em: 12 jun. 2013.

LEWGOY, Alzira. Pensar a Supervisão de Estágio em Serviço Social: ser ou não ser, eis a questão! Tese (Doutorado em Serviço 
Social) - Pontifícia Universidade Católica do Rio Grande do Sul PUCRS, Porto Alegre 2007.

LEWGOY, Alzira, MACIEL, Ana Lúcia, Reflexões acerca do Ensino a distância na Formação em serviço Social. Revista Temporalis: Estado e educação Superior - Questões e Impactos no serviço Social, Brasília: DF, n. 15, ano VIII, 2008.

LEWGOY, Alzira et al. A produção de conhecimento sobre formação em Serviço Social: aproximações com o estado da arte. In: ENCONTRO NACIONAL DE PESQUISADORES EM SERVIÇO SOCIAL - ENPESS, 13., 2012, Juiz de Fora. Anais... Juiz de Fora: ABEPSS, 2012.

LIMA, Katia. Contra-reforma na educação superior: de FHC a Lula. São Paulo: Xamã, 2007.

MACIEL, Ana Lúcia Suárez. Universidade em crise: uma travessia necessária para a formação em Serviço Social. Tese (Doutorado) - Pontíficia Universidade Católica do Rio Grande do Sul - PUCRS, Porto Alegre, 2006. Disponível em: <http://tede.pucrs.br/tde_ busca/arquivo.php?codArquivo=123>. Acesso em: 12 jun. 2013.

MENDES, Jussara Maria R. Gestão ABEPSS. 2003-20004. Quem é de Luta Avança. Revista Serviço Social \& Sociedade, Brasília: ABEPSS, ano 11, n. 22, jul./dez. 2011.

PLATAFORMA Carlos Chagas do CNPq. Disponível em: <http://carloschagas.cnpq.br>. Acesso em: 12 jun. 2013.

PORTAL CAPES. Disponível em: <http://www.capes.gov.br>. Acesso em: 12 jun. 2013.

REIDEL, Tatiana. A indissociabilidade entre o Projeto ÉticoPolítico e a formação profissional: uma materialização em xeque. Tese (Doutorado) - Pontíficia Universidade Católica do Rio Grande do Sul - PUCRS, Porto Alegre, 2010. 